\title{
Genome-Wide DNA Methylation Variations upon Exposure to Engineered Nanomaterials and Their Implications in Nanosafety Assessment
}

\author{
Yue Chen, Ming Xu, Jie Zhang, Juan Ma, Ming Gao, Zhihong Zhang,* Yong Xu, \\ and Sijin Liu*
}

With the rapid development of nanotechnology and the growing application of engineered nanomaterials (ENMs) in industrial processes and consumer products public concern is raised regarding their potential impacts on the environment and human health, ${ }^{[1]}$ Mounting efforts are being devoted to nanosafety assessment and safer design of ENMs using in vitro and in vivo approaches; however, a conclusive understanding on nanosafety has not been reached yet and a validated framework for human health risk assessment remains to be established, ${ }^{[2]}$ Given the novel and unique physical, chemical, elastic, and mechanical properties of ENMs, traditional toxicity assays that were developed originally for bulk materials or chemicals may not be suitable for the reliable detection of direct nanotoxic effects and indirect effects, such as compensatory adaptation and the secondary impairments. For example, many ENMs did not show toxicity using the traditional toxicity assays, especially at sublethal or relatively low concentrations, ${ }^{[3,4]}$ due to the low sensitivity of the methods. Thus, more sensitive methodologies are needed to evaluate their safety profiles.

To date, systems-based approaches have been used at transcriptome (including mRNAs and noncoding RNAs) and proteome levels to assess nanosafety, ${ }^{[5]}$ By contrast, the epigenomic analysis has not received sufficient attention for nanosafety assessment. DNA methylation is an early sensitive parameter in response to a wide range of exogenous and endogenous stimuli including ENMs. ${ }^{[6,7]}$ However, there is a little understanding on this front, and, to the best of our knowledge, limited data are available for genome-wide DNA methylation changes caused by ENM exposure. As a vital mechanism of epigenetic regulation, DNA methylation changes fundamentally

Dr. Y. Chen, Dr. M. Xu, J. Zhang, Dr. J. Ma,

Dr. M. Gao, Prof. S. Liu

State Key Laboratory of Environmental

Chemistry and Ecotoxicology

Research Center for Eco-Environmental Sciences

Chinese Academy of Sciences

Beijing 100085, China

E-mail: sjliu@rcees.ac.cn

Dr. Y. Chen, Prof. Z. Zhang, Prof. Y. Xu

Department of Urology

The Second Hospital of Tianjin Medical University

Tianjin Institute of Urology

Tianjin 300211, China

E-mail:drzhangzhihong@163.com

DOI: 10.1002/adma.201604580 dictate gene expression levels to fine-tune cellular homeostasis, ${ }^{[8]}$ which can be specifically used to understand cellular responses upon sublethal low-dose ENM exposure.

In this study, to comprehend the variations of DNA methylation induced by ENMs with high exposure risk, we performed base-pair resolution DNA methylation sequencing together with toxicological and functional assays. Taking in consideration the production volume, applications and the exposure potential, ${ }^{[1,9]}$ six types of ENMs were selected including metal and metal oxide nanomaterials: silver nanoparticles (AgNPs), gold nanoparticles (AuNPs), $\mathrm{TiO}_{2}$ nanoparticles $\left(\mathrm{nTiO}_{2}\right)$, and $\mathrm{ZnO}$ nanoparticles ( $\mathrm{nZnO}$ ), and carbonaceous nanomaterials: carbon nanotubes (CNTs) and graphene oxide (GO). The overall design of this study is depicted in Figure 1A. First, characterizations of the ENMs were performed, as described in Figure 1B,C and Figures S1-S3 (Supporting Information). Based on the primary exposure route (i.e., oropharyngeal aspiration ${ }^{[10]}$ ) and the major excretion pathway through urine, ${ }^{[11]}$ lung-derived A549 cells (widely accepted alveolar epithelial model cells ${ }^{[12]}$ ) and kidney-derived HEK293T (293T) cells ${ }^{[13]}$ were selected for the exposure studies. Here, we referenced the estimated exposure doses in the real exposure scenario for metal-based ENMs $^{[14]}$ and carbonaceous ENMs, ${ }^{[15]}$ which could more realistically and accurately determine the risks of ENMs in interfering with DNA methylation in the actual exposure settings. In fact, exposure to ENMs at these concentrations induced only minimal reduction of cell viability $(<\approx 10 \%)$ without significant cell death, as shown in Figure S4 (Supporting Information). The marginal increase of lactate dehydrogenase (LDH) release and propidium iodide (PI)/To-Pro-3 staining further confirmed the mild cytotoxicity of these ENMs (Figure S5A-D, Supporting Information) at the tested doses. Transmission electron microscopy (TEM) analysis revealed the membrane and intracellular localization of these ENMs in A549 and 293T cells (Figure S6, Supporting Information), indicating the active adsorption and endocytosis of these ENMs by cells. No significant general reactive oxygen species (ROS) generation was found in both A549 and 293T cells following ENM treatment over the time course, i.e., 1, 3, 6, and $24 \mathrm{~h}$ (Figures S7 and S8, Supporting Information). Meanwhile, as evidenced by the MitoSOX fluorescent intensity analysis, there was also no significant difference in mitochondrial ROS production upon ENM exposure, relative to the untreated control (Figures S9-S11, Supporting Information). Importantly, no DNA damage was observed in A549 and 293T cells treated with all six ENMs at sublethal concentrations, as reflected by the fact of no induction of $\gamma-\mathrm{H} 2 \mathrm{AX}$ and 8-oxo-G 
(A)

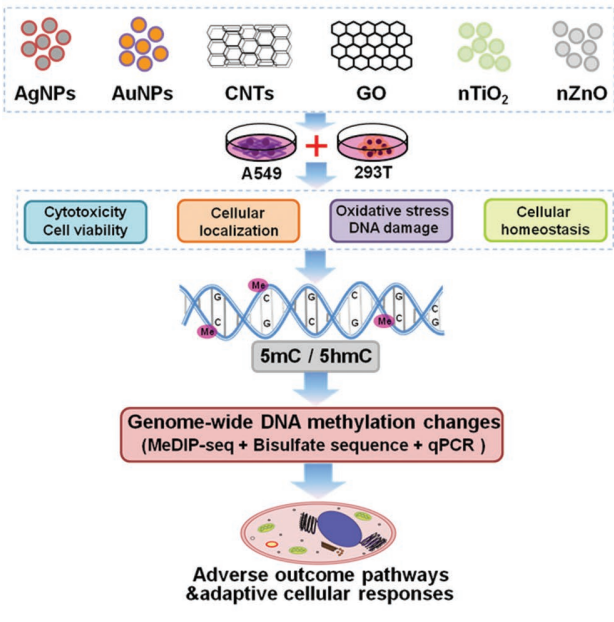

(B)

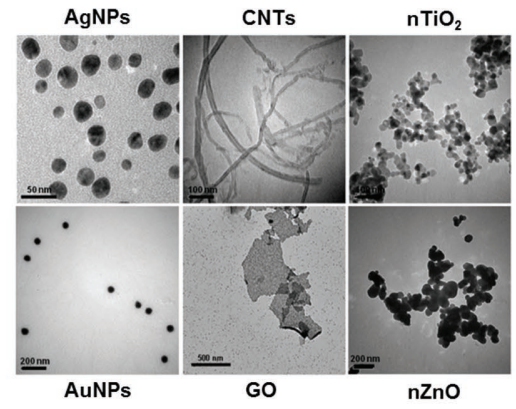

(C)

\begin{tabular}{|c|c|c|c|c|c|}
\hline NMs & & $\begin{array}{l}\text { Length or } \\
\text { lateral size }\end{array}$ & $\begin{array}{l}\text { Thick } \\
\text {-ness }\end{array}$ & $\mathrm{H}$ & hap \\
\hline AgNPs & $5 \mathrm{~nm}$ & - & - & $79 \pm 1 \mathrm{~nm}$ & Sphere \\
\hline INPs & & - & - & $4 \pm$ & \\
\hline CNTs & $\begin{array}{l}2-25 \mathrm{~nm} \\
0-12 \mathrm{~nm}\end{array}$ & $392 \pm 57 \mathrm{~nm}$ & - & - & Fiber-like \\
\hline so & $-1-1$ & $4 \pm 65 n$ & $1 \mathrm{~nm}$ & - & 2D sheet \\
\hline $\mathrm{TiO}_{2}$ & $25 \mathrm{~nm}$ & - & - & $2321 \pm 248 \mathrm{~nm}$ & Sphere \\
\hline $\mathrm{ZnO}$ & $20 \mathrm{~nm}$ & - & - & $1441 \pm 69 \mathrm{~nm}$ & Sphere \\
\hline
\end{tabular}

Figure 1. Overall experimental design and characterization of ENMs. A) Schematic diagram of the overall experimental design. B) Representative TEM images of ENMs used in this study. C) Physicochemical characterization of ENMs used in this study. For multiwall CNTs, the inner and outer diameters are provided. Dash (-) indicates not applicable.

levels in comparison with untreated cells (Figures S12 and S13, Supporting Information).

Afterward, we continued to look into the variations of the genome-wide DNA methylation signatures. The methylated form of cytosine (5-methylcytosine, namely 5 -mC) primarily exists in $\mathrm{CpG}$ dinucleotides, and 5-hydroxymethylcytosine $(5-\mathrm{hmC})$ is the oxidized derivative of 5-mC. ${ }^{[16]}$ As DNA methylation plays a fundamental role in the transcriptional activity for nearly the whole genome, the levels of 5-mC and 5-hmC indicate the methylation status of DNA. ${ }^{[8,17]}$ Thus far, the variations of DNA methylation upon ENM exposure on the genome-wide scale remain largely unexplored; however, these data are important in unraveling the early molecular events and cellular pathways perturbed in response to ENMs, especially under low-dose exposure. To this end, we here studied the impact of ENMs on genome-wide DNA methylation using a series of strategies. First, the amounts of 5-mC and 5-hmC in genomic DNA were measured through ultraperformance liquid chromatographytandem mass spectrometry (UPLC-MS/MS). The heat map of UPLC-MS/MS results depicted the relative changes of 5-mC and 5-hmC levels following ENM exposure, relative to the untreated control (Figure 2A,B). Overall, AgNPs and GO elicited great changes of 5-mC levels in A549 and 293T cells, while the other four types ENMs caused no significant changes (Figure 2A). AgNPs increased 5-mC levels in A549 and 293T cells; in particular, a $\approx 1.5$-fold increase in 5 -mC levels was observed for AgNPs at $2 \mu \mathrm{g} \mathrm{mL} L^{-1}$ in A549 cells and at $4 \mu \mathrm{g} \mathrm{mL}^{-1}$ in 293T cells, respectively (Figure $2 \mathrm{C}, P<0.05$ ). GO exposure also promoted 5-mC levels in these two cell lines, with a maximum increase at $50 \mu \mathrm{g} \mathrm{mL}^{-1}$ (Figure 2A,D, $P<0.05$ ). These findings suggested higher abilities of AgNPs and GO to alter genomic DNA methylation levels. By contrast, the variations of 5-hmC appeared much weaker than those of 5-mC in both A549 and 293T cells upon all ENMs, and the total 5-hmC levels changed slightly in either direction for both cell lines (Figure 2B). The above results were validated via dot-blotting analysis of 5-mC and 5-hmC, which also demonstrated that AgNPs and GO induced greater increase of 5-mC levels in A549 and 293T cells, compared with the other ENMs (Figure 2E,F). In contrast to $5-\mathrm{mC}$, the dot-blotting results showed marginal changes of the 5-hmC level (Figure 2E,F), analogous to the results from the UPLC-MS/MS assay. Different from these parenchymal cells, macrophages take a leading role in clearing exogenous particles. ${ }^{[18]}$ Thus, we further compared DNA methylation changes of THP-1 cells (human macrophages) relative to A549 and HEK293T cells. As shown in Figure S14 (Supporting Information), dot blotting results revealed that GO and AgNPs also induced an increase in 5-mC content in THP-1 cells, compared with untreated cells. These results together evidenced that ENM exposure (especially for AgNPs and GO) elevated the amount of 5-mC in genomic DNA in parenchymal cells and macrophages.

To interpret the above findings, the processes of DNA methylation and demethylation were investigated. DNA methylation, conducted by methyltransferases (DNMTs), usually occurs at the 5th position of the cytosine residue (namely 5-mC) and mostly within CpG islands. ${ }^{[19]}$ Increased methylation, especially at the promoter region, usually leads to repressed gene expression by hindering the binding of transcriptional factors, whereas reduced methylation is reversely associated with enhanced mRNA expression. ${ }^{[20]}$ The promoter regions of $70 \%$ mammalian genes contain ample CpG islands, and these islands are normally unmethylated for active gene expression. ${ }^{[20]}$ In contrast to 5-mC, human genomic DNA harbors a very small proportion of $5-\mathrm{hmC}$, with $<0.5 \%$ in kidney and $<0.2 \%$ in lung. ${ }^{[21]}$ Although the actual function of $5-\mathrm{hmC}$ is still unknown in epigenetics thus far, the conversion of 5 - $\mathrm{mC}$ to 5 -hmC catalyzed by ten-eleven translocation (TET) family members is believed to play an important role in modulating gene expression. ${ }^{[22]}$ Thereafter, we studied the changes of DNMTs and TETs following ENM exposure. As shown in 
(A)

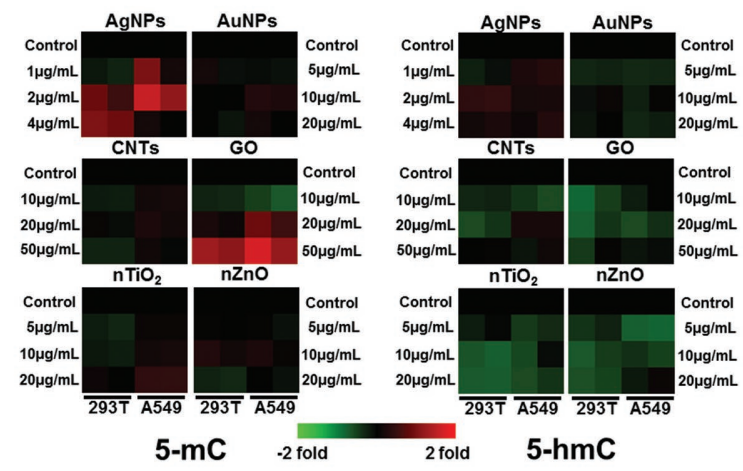

(C)

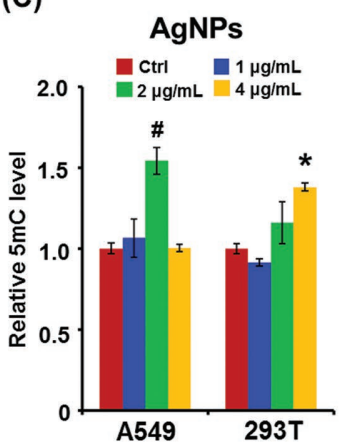

(B)

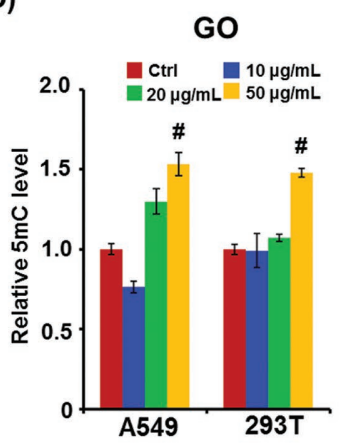

(E)

(G)

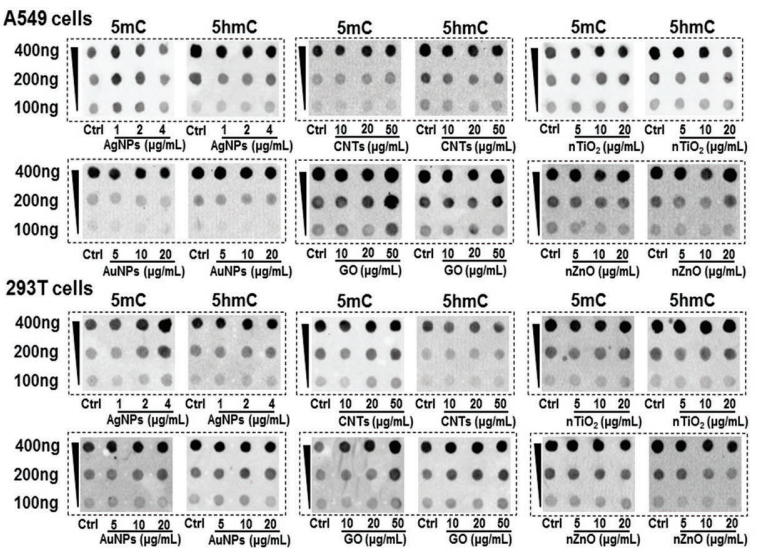

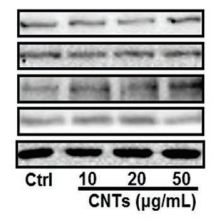
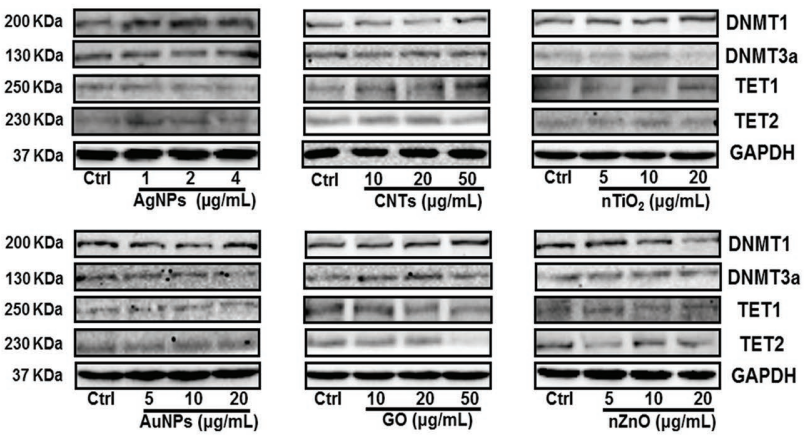

Figure 2. Global DNA methylation changes upon various ENMs. A,B) Heat map graphical representations of the relative values of $A)$ - $m C$ and B) 5 -hmC in genomic DNA of A549 and 293T cells upon ENMs for $24 \mathrm{~h}$, based on the results from the UPLC-MS/MS assay. C,D) Quantitative analysis of 5-mC values in genomic DNA determined by UPLC-MS/MS in A549 and 293T cells upon C) AgNPs and D) GO at various concentrations for $24 \mathrm{~h}$ $(n=2-4)$. *: $P<0.05$, \#: $P<0.01$, relative to untreated control. E,F) Immunodot-blotting analysis of 5-mC and 5-hmC levels in E) A549 and F) 293T cells upon exposure to ENMs at different concentrations for $24 \mathrm{~h}$. The amount of loaded DNA was denoted in the left side of autoradiogram images. G) Western blot analysis of DNMT1, DNMT3a, TET1, and TET2 concentrations in A549 cells upon ENMs for 24 h. Glyceraldehyde-3-phosphate dehydrogenase (GAPDH) was used as the loading control.

Figure 2G and Figure S15 (Supporting Information), AgNPs and GO increased the concentrations of DNMT1 and DNMT3a and reversely decreased the amount of TET1 and TET2 in A549 and 293T cells, supporting the finding of increased global 5-mC mass (Figure 2A,C,D). Relative to AgNPs and GO, other ENMs incurred weaker changes of DNMTs and TETs (Figure 2G and Figure S15, Supporting Information). These results suggested that ENM-induced changes of DNMTs and TETs could contribute to the global alterations of DNA methylation, implying that the processes of both methylation and demethylation are vulnerable to ENM exposure. Collectively, these findings uncovered that AgNPs and GO manifested greater capability to alter DNA methylation than other ENMs. To this end, AgNPs and GO were selected for the following mechanistic investigation.

Subsequently, we assessed the changes of DNA methylation for specific genes with genome-wide methylated DNA immunoprecipitation sequencing (MeDIP-Seq). As shown in Figure 3A, the global DNA methylation level in A549 cells upon AgNPs and GO exposure were greater than in the untreated cells, especially for GO-treated cells, similar to the results from UPLC-MS/MS and the dot-blotting assay (Figure 2A-E). When looking at the distribution of DNA hypermethylation in the genome, a universal increase was observed in transcription start sites (TSS), gene body regions, transcription end sites (TES), and upstream and downstream regions as well (Figure 3A).
The methylation pattern analysis revealed that increased peaks were located across the promoter region to the downstream region, especially in the promoter regions and within the exons and introns (Figure 3B). Moreover, GO-treated cells showed a greater increase of peaks than AgNP-treated cells (Figure 3B). Similar to the results in A549 cells, increased global DNA methylation was found in 293T cells following AgNP or GO treatment, but to a smaller extent (Figure S16A,B, Supporting Information). DNA methylation predominantly occurs on cytosine residues of $\mathrm{CpG}$ dinucleotides followed by guanine bases. ${ }^{[8]}$ Genomic regions with higher CpG density are susceptible to being hypomethylated, whereas those with lower $\mathrm{CpG}$ density tend to be hypermethylated.[23] The distribution of $\mathrm{CpG}$ density in 5 -mC peaks was therefore determined (Figure 3C), showing a CpG density-dependent distribution pattern in 5-mC peaks. The proportion of $0-20 \mathrm{CpGs}$ accounted for nearly $50 \%$ of all 5 -mC peaks, and there was increased 5-mC peak distribution in low-density $\mathrm{CpGs}$ in GO-treated cells, compared with untreated cells and AgNP-treated cells (Figure 3C). These data suggested that GO-induced DNA hypermethylation also occurred in the regions with low $\mathrm{CpG}$ density. Additionally, a similar distribution profile was observed in 293T cells (Figure S16C, Supporting Information).

To identify the possible alterations in gene transcription due to differential DNA methylation upon AgNPs and GO exposure, 
(A)

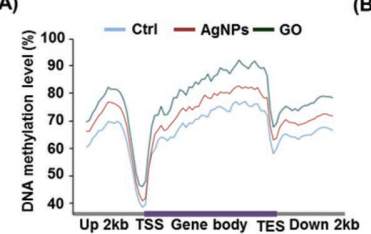

(C)

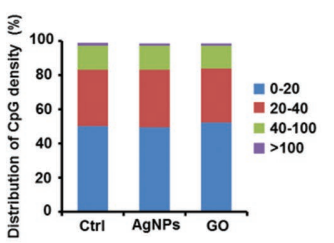

(E)

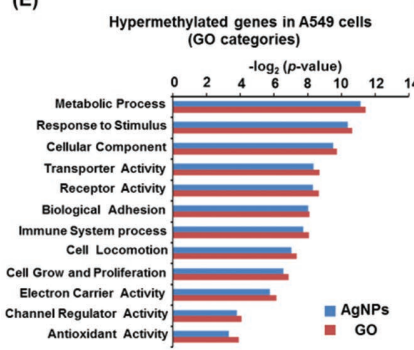

(B)

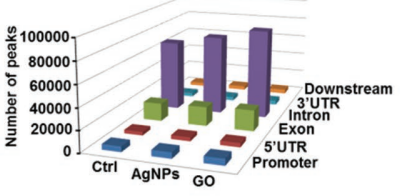

(G)

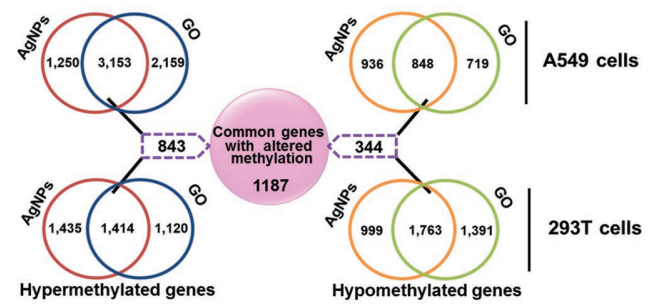

(H)

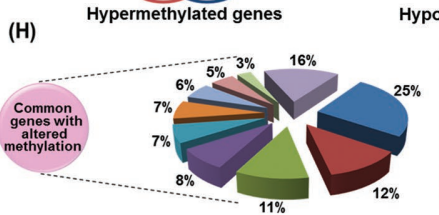
Cytoskeleton - Vesicle associated protein Eellular adhesion, migration and junction - Ion channels/transporters Energy homeostasis and mitochondrion Ubiquintin-related protein degradation Transpo
Others

(I)

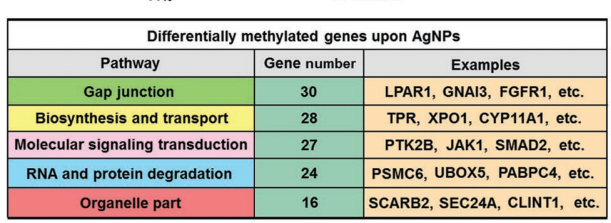

(F)

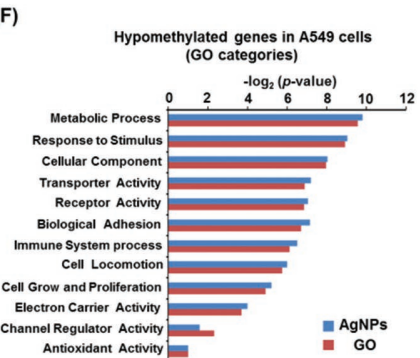

\begin{tabular}{|c|c|c|}
\hline \multicolumn{3}{|c|}{ Differentially methylated genes upon GO } \\
\hline Pathway & Gene number & Examples \\
\hline Receptor signaling pathway & 40 & SDC1, CHRM2, JMJD6, etc. \\
\hline Molecular signaling transduction & 33 & RAP1B, SESN1, MAPKAPK2, etc. \\
\hline Substance metabolism process & 31 & PDE5A, GFPT1, ACOX3, etc. \\
\hline Focal adhesion & 23 & COL4A2, SOS1, CHN1, etc. \\
\hline Inflammation and immune & 14 & LTBP2, IL15, FSTL1, etc. \\
\hline
\end{tabular}

Figure 3. Distribution of DNA methylation changes in different genomic regions and ontology analysis of differentially methylated genes in cells responding to AgNPs and GO. A) Average DNA methylation levels in A549 cells treated with AgNPs and GO. The genes were generally divided into three regions, a $2 \mathrm{~kb}$ region upstream of the TSS, the gene body from the TSS to the TES, and a $2 \mathrm{~kb}$ region downstream of TES. B) Distribution of DNA methylation peaks in different genomic regions for A549 cells upon AgNPs and GO exposure. C) Relative distribution percentage of different $\mathrm{CpG}$ densities within 5-mC peaks in A549 cells exposed to AgNPs and GO. D) Distribution analysis of hypermethylated and hypomethylated genes in different genomic regions for A549 cells responding to AgNPs and GO. E,F) Gene ontology and pathway analysis of E) hypermethylated genes and F) hypomethylated genes in A549 cells treated with AgNPs and GO. G) Area-proportional Euler diagram illustrating the common genes with constant methylation change patterns in A549 and 293T cells upon either AgNPs or GO. H) Classification of the common genes obtained in (G). Pathway analysis of the differentially methylated genes upon I) AgNPs and J) GO.

genes that were significantly either hypermethylated or hypomethylated were classified. As shown in Figure 3D, the number of hypermethylated genes was three to four times greater than that of hypomethylated genes for both AgNPs and GO. Moreover, the sites of methylation changes were mostly located in introns and exons of genes in A549 cells upon AgNPs and GO exposure (Figure 3D), consistent with the results of 5-mC peak distribution (Figure 3B). Similarly, methylation changes were also found in introns and exons of genes for 293T cells upon AgNPs and GO exposure (Figure S16D, Supporting Information). Furthermore, functional modeling for differentially methylated genes was carried out with the gene ontology analysis. As shown in Figure 3E,F and Figure S17A,B (Supporting Information), many differentially methylated genes were involved in a large array of biological processes and functions relevant to various aspects of cellular homeostasis, such as metabolic processes, cellular components, transporters, and receptors. With these results, we hypothesized that AgNPs and GO could pose a greater impact on cellular homeostasis and priming state due to differential DNA methylation (Figure 3E,F and Figure S17A,B, Supporting Information). To test this hypothesis, we further classified the genes with hypermethylation and hypomethylation. As depicted in Figure 3G, there were 3153 commonly hypermethylated genes in A549 cells upon AgNPs and GO exposure, with 1250 and 2159 genes hypermethylated differently in response to AgNPs and GO, respectively. The total number of hypomethylated genes was much smaller than that of hypermethylated genes for both AgNPs and GO (Figure 3G). There were 848 common genes for AgNP- and GO-treated A549 cells, with 936 and 719 genes found differently for AgNPs and GO, respectively (Figure 3G). Relative to A549 cells, the number of hypermethylated genes was much smaller for both AgNP and GO treatment in 293T cells (Figure 3G, >35\% and $>50 \%$ reduction, respectively), implying that A549 cells are more prone to be hypermethylated following ENM exposure than $293 \mathrm{~T}$ cells. There were 1414 hypermethylated genes in common between AgNPs and GO when exposed to 293T cells, with 1435 and 1120 differentially hypermethylated genes for AgNPs and GO in 293T cells, respectively (Figure 3G). Meanwhile, there were 1763 genes that were commonly hypomethylated in 293T cells following AgNP or GO treatment, with 999 and 1391 genes that were differentially hypomethylated in 293T cells following AgNP or GO treatment, respectively (Figure 3G). In total, 1187 common genes were identified to be differentially methylated in both A549 cells and 293T cells for both AgNPs and GO.

To evaluate the significance of the commonly methylated genes ( $n=1187)$, categorization was implemented. The commonly affected pathways were prominently plasma membrane-associated receptors and components, cytoskeleton 
and adhesion/junction-related proteins, ion channels/transporters and energy homeostasis (Figure $3 \mathrm{H}$ ). Considering the distinct physicochemical properties between AgNPs and GO, pathway analysis was further performed for the differentially methylated genes (Figure 3I,J). A multitude of genes were found differentially methylated between AgNPs and GO in both A549 and 293T cells, including genes responsible for gap junction (e.g., LPAR1 and GNAI3) ${ }^{[24]}$ upon AgNPs exposure and genes encoding proteins involved in substance metabolism (e.g., PDE5A and GFPT1) ${ }^{[25]}$ upon GO exposure. These differences between AgNPs and GO could be attributed to their distinct physicochemical properties and their different mode of interaction with cells including differential subcellular localization. ${ }^{[26-29]}$ For example, AgNP dissolves ions, and Ag ions play a major role in AgNP-induced toxic effects; ${ }^{[26]} \mathrm{GO}$ have different lateral sizes and surface functional groups and have strong association with biomolecules. ${ }^{[27]}$ Therefore, we looked into the changes of 5-mC levels responding to $\mathrm{Ag}$ ions and $\mathrm{GO}$ with different lateral sizes and surface modifications. Previous studies demonstrated that Ag particles and Ag ions simultaneously existed inside the cells with a release rate of $\mathrm{Ag}$ ions around $10 \% .{ }^{[28,30]}$ Thus, $\mathrm{Ag}$ ions at $0.4 \mu \mathrm{g} \mathrm{mL} \mathrm{m}^{-1}$ were used to treat cells, and different from Ag particles, Ag ions did not induce a significant change in 5-mC content in A549, 293T, and THP-1 cells (Figure S14, Supporting Information). In order to answer whether length/size contributes to the influence on DNA methylation induced by ENMs, we deliberately prepared an array of GO with different lateral size, i.e., S-GO (smallest), I-GO (intermediate), and L-GO (largest), as described in our recent report. ${ }^{[28]}$ As shown in Figure S18 (Supporting Information), no significant difference could be found among these sizedGO in increasing 5-mC levels in A549 and 293T cells. Furthermore, we scrutinized the effect of surface modification on DNA methylation changes using GO-NH $\mathrm{H}_{2}$ and GO-PEG (polyethylene glycol coated GO), as described in our recent study. ${ }^{[31]}$ As shown in Figure S19 (Supporting Information), compared with the parental GO and GO-NH$H_{2}$, GO-PEG induced a milder increase of 5-mC levels in A549 and 293T cells, in agreement with the greater biocompatibility of GO-PEG. ${ }^{[31]}$ Taken together, these data revealed new insights into the structure-activity relationship for AgNPs and GO: Ag nanoparticles rather than dissolved Ag ions were responsible for the DNA methylation changes; the surface activity of GO rather than its size played the major role in GO-induced DNA alternations. However, further studies should be considered to identify the physicochemical determinants and nanobio interactions (e.g., distinct subcellular localizations) in inducing different signatures of DNA methylation for diverse ENMs in the future.

To uncover the downstream outcome, i.e., the possible adverse outcome pathways (AOPs) and adaptive pathways upon ENM-induced DNA methylation changes, we determined the expression of hypermethylated genes (namely gene dose changes) through reverse transcription quantitative Polymerase Chain Reaction (RT-qPCR). We deliberately selected genes on the basis of the gene functional mapping results (Figure 3), including those responsible for membrane integrity and signal transduction (PCDH7, CNTN5, AIG1, EXT1, ABCC5, etc.), cytoskeleton maintenance and cell adhesion and migration (ARHGAP24, TBC1D5, ARHGAP12, SYTL3, ARHGAP19, etc.), ion channels and transporters (CACNA1B, SLC12A6, CACNA1D, KCNJ6, CACNA2D3, etc.) and energy homeostasis (CFTR, HEM2, AK5, PCCA, SLC25A21, etc.). The qPCR results manifested that the transcription of most genes was greatly suppressed in A549 cells treated with AgNPs and GO, compared with the untreated control (Figure 4A, $P<0.05$ ). These findings thus demonstrated the consistency between repressed gene expression and DNA hypermethylation. Of note, there were some genes that were not constantly reduced at the mRNA level for both AgNPs and GO treatments (Figure S20, Supporting Information), demonstrating the complex regulation on gene dose through DNA methylation upon different ENMs. To substantiate the contribution of DNA hypermethylation to reduced gene dose, we further specifically inspected the methylation patterns of representative genes. Significant accumulation of DNA methylation within the promoter regions was observed for ABCC5, SYTL3, CACNA2D3, and PCCA in according chromosome segments in A549 cells upon AgNPs or GO exposure, relative to untreated cells (Figure 4B). The locusspecific bisulfite sequencing (BSP) technique was thereafter employed to confirm the above findings. The methylation levels within the promoter regions for these genes were elevated in cells treated with AgNPs or GO, compared with the untreated control (Figure 4C), correlating with reduced expression of these genes.

The common differentially methylated genes (as described in Figure 3) were grouped based on their roles in maintaining overall cellular homeostasis (e.g., ion and energy homeostasis) or in conducting differential functions, such as membrane integrity and cellular adhesion (Figure 5A). To decipher the significance of possible AOPs and adaptive signaling pathways due to DNA methylation changes, cytotoxic and physiological manifestations coupled to the functions of those grouped genes (Figure 5A) were tested in A549 cells upon AgNPs and $\mathrm{GO}$ exposure. The plasma membrane is an essential barrier to sustain cellular morphology and physiological functions and to protect cells against intruding pathogens, thus membrane permeability determination is used as a marker to characterize the membrane integrity. ${ }^{[32]}$ Albeit slightly, an increase of membrane permeability in AgNP- or GO-treated cells, as evidenced by PI and To-Pro-3 staining and the extracellular LDH release (Figure S5, Supporting Information), was in analogy to reduced expression of genes responsible for membrane integrity including PCDH7, CNTN5, AIG1, EXT1, and ABCC5 (Figure 4A). The slight increase of LDH release could be a surrogate of compromised integrity of membrane cytoskeleton. ${ }^{[3]}$ Meanwhile, cytoskeleton plays an important role in maintaining cellular morphology and in controlling cell adhesion and migration. Due to the downregulation of genes (including ARHGAP24, TBC1D5, ARHGAP12, SYTL3, and ARHGAP19) that are responsible for cytoskeleton assembly and adhesion/ junction regulation (Figure 4A), the density of actin meshwork was reduced in A549 and 293T cells upon AgNPs and GO exposure (Figure 5B and Figure S21A, Supporting Information), indicative of impaired assembly of actin fibers and undermined stress fiber formation. Moreover, in parallel to the reduction of CACNA2D3 that encodes a component in the $\mathrm{Ca}^{2+}$ channel complex (Figure 4A), a rightward shift of Fluo-3 fluorescence was observed in AgNP- and GO-treated cells, relative 


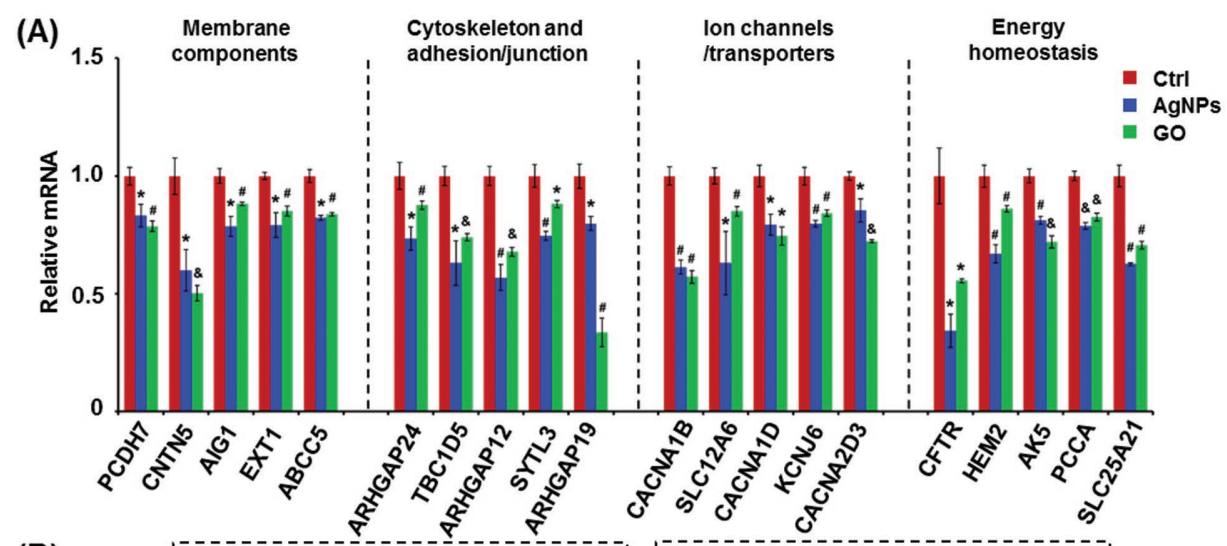

(B)
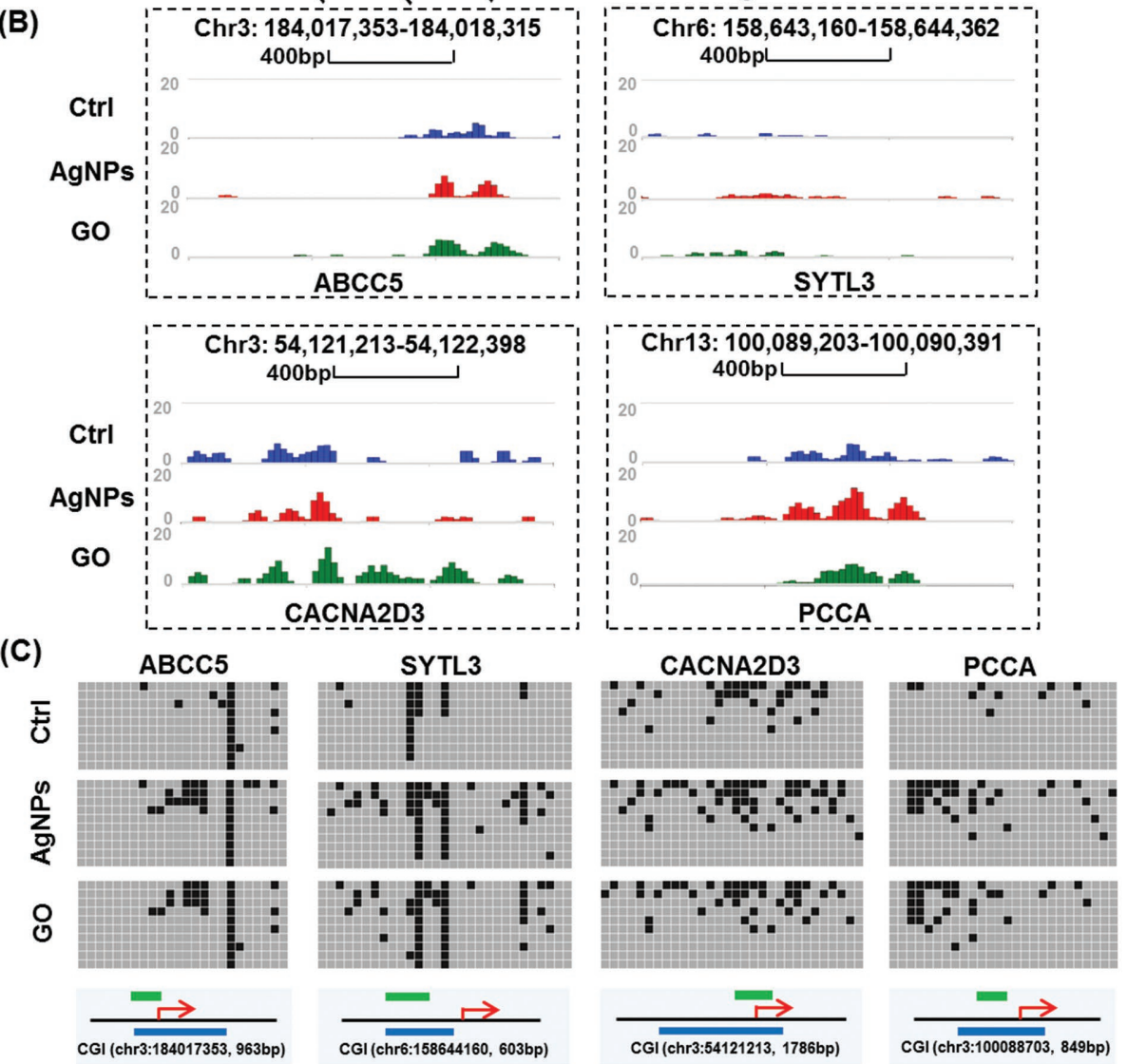

Figure 4. Gene expression analysis by RT-qPCR and BSP analysis for genes. A) RT-qPCR analysis of selected hypermethylated genes in A549 cells following AgNP and $\mathrm{GO}$ exposure. *: $P<0.05, \#: P<0.01, \&: P<0.001$, relative to untreated control. B) Representative UCSC Genome Browser snapshots of MeDIP-Seq results showing the distribution of 5-mC densities in ABCC5, SYTL3, CACNA2D3, and PCCA gene promoter regions in A549 cells upon AgNPs and GO exposure. Scale bars were equalized across all samples. C) BSP results for the promoter regions of ABCC5, SYTL3, CACNA2D3, and PCCA. Black squares denote methylated $\mathrm{CpGs}$, whereas gray squares represent unmethylated $\mathrm{CpGs}$. In the lower panel, red arrows indicate transcriptional start sites, blue bars denote CGIs, and green bars show the location of amplified fragments for bisulfite sequencing.

to untreated cells, indicating significant $\mathrm{Ca}^{2+}$ influx in response to AgNPs and GO (Figure 5C and Figure S21B, Supporting Information). Additionally, energy metabolism was determined through measuring Adenosine Triphosphate (ATP) synthesis. A $20-25 \%$ decline of cellular ATP content was verified in A549 cells and 293T cells upon AgNPs exposure, compared with untreated cells (Figure 5D and Figure S21C, Supporting Information, $P<0.05$ ). In contrast to AgNPs, elevated ATP production (approximately 25\%) was observed in GO-treated A549 and 293T cells (Figure 5D and Figure S21C, Supporting Information, $P<0.05$ ), showing different adaptive responses in energy metabolism to AgNPs. Collectively, dysfunctions of thw plasma membrane, cytoskeleton, ion channel/transporters, and energy metabolism would converge onto overall cellular homeostasis; in other words, these dysfunctions would impair the global priming state of cellular equilibrium, such as overall 


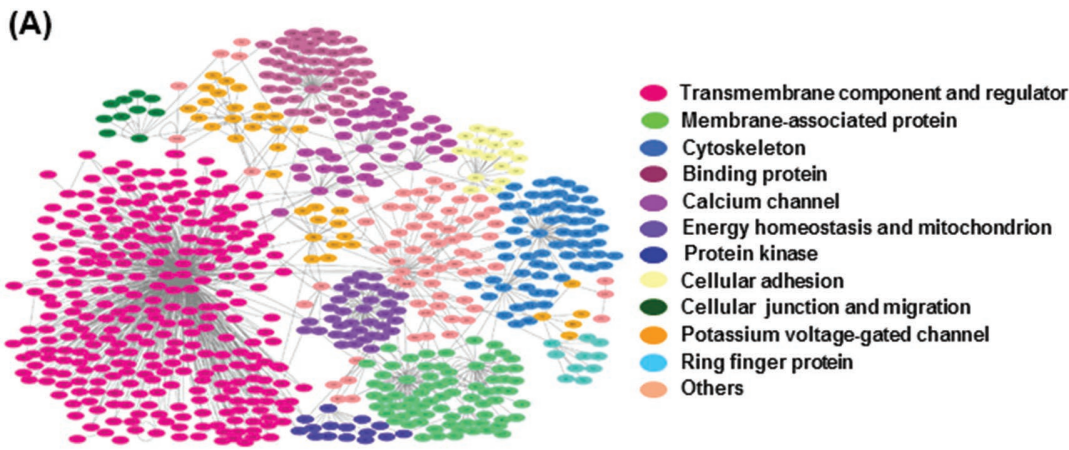

(B)

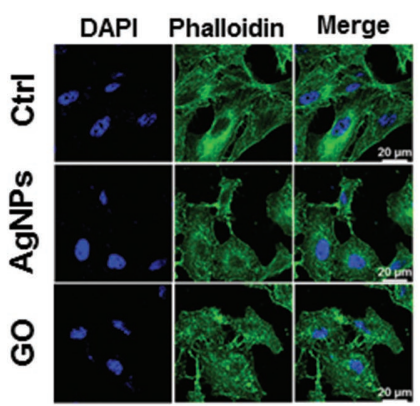

(C)

(D)

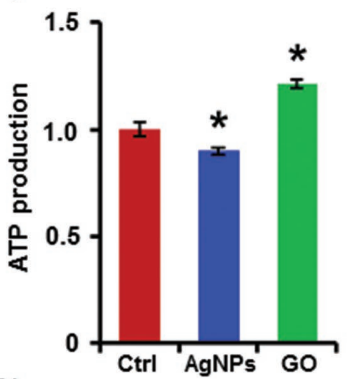

(E)

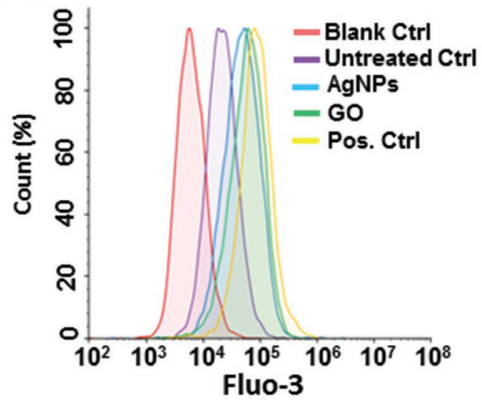

(F)

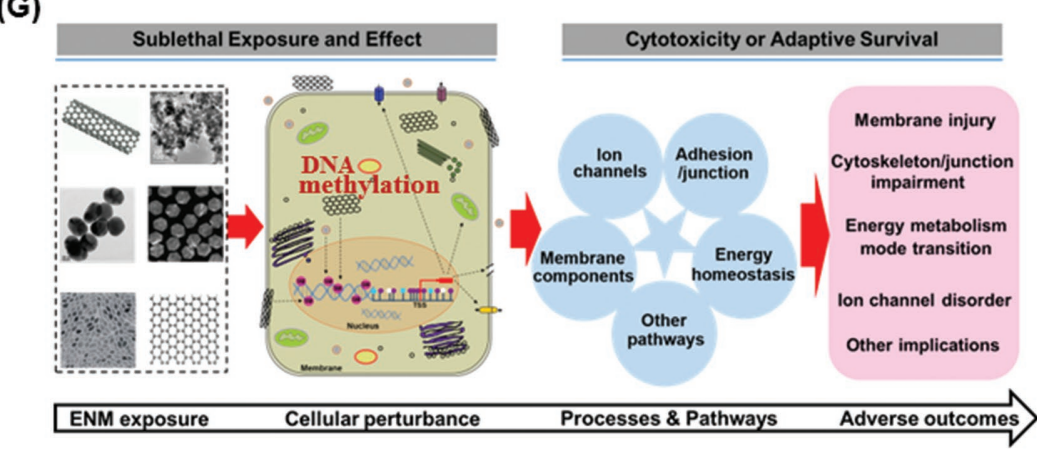

Figure 5. Toxicological and functional analyses associated with AOPs and adaptive/compensatory signaling pathways. A) Pathway network analysis of the common differentially methylated genes. The cycle nodes represent genes, and each color represents a class of cellular functions or processes. Lines indicate interaction between genes. B) Cytoskeletal staining with phalloidin (shown in green) examined by confocal microscopy for A549 cells treated with $2 \mu \mathrm{g} \mathrm{mL}^{-1}$ AgNPs and $50 \mu \mathrm{g} \mathrm{mL}^{-1} \mathrm{GO}$ for $24 \mathrm{~h}$. Cell nuclei were counter-stained with DAPI (in blue). C) Intracellular $\mathrm{Ca}^{2+}$ concentration in A549 cells after exposure to $2 \mu \mathrm{g} \mathrm{mL} \mathrm{L}^{-1} \mathrm{AgNPs}$ and $50 \mu \mathrm{g} \mathrm{mL}-1 \mathrm{GO}$ for $24 \mathrm{~h}$, determined by FACS analysis using the Fluo-3/AM probe $(n=3)$. D) Relative cellular ATP production in A549 cells upon $2 \mu \mathrm{g} \mathrm{mL}^{-1} \mathrm{AgNPs}$ and $50 \mu \mathrm{g} \mathrm{mL} \mathrm{L}^{-1} \mathrm{GO}$ for $24 \mathrm{~h}$. Bioluminescent intensity reflecting the cellular ATP level was examined with a microplate reader $(n=4)$. E) Relative total RNA amount in A549 cells after treatment with $2 \mu \mathrm{g} \mathrm{mL}^{-1}$ AgNPs and $50 \mu \mathrm{g} \mathrm{mL}^{-1} \mathrm{GO}$ for $24 \mathrm{~h}(n=4)$. F) Relative total protein mass in A549 cells after exposure to $2 \mu \mathrm{g} \mathrm{mL}-1$ AgNPs and $50 \mu \mathrm{g} \mathrm{mL}-1 \mathrm{GO}$ for $24 \mathrm{~h}(n=4)$. G) The overall schematic protein translation and RNA synthesis. ${ }^{[34]}$ Diminished activity of protein and RNA production is an adaptive/compensatory mechanism for cell survival under exogenous and endogenous stresses.[35] Thereby, in agreement with the above findings, a 10-15\% drop of global protein content and RNA mass were observed in A549 and 293T cells upon AgNPs and GO exposure (Figure 5E,F and Figure S21D,E, Supporting Information, $P<$ 0.05). Thus, our combined results delineated the changes of cell physiology, adverse outcomes, and homeostatic adaptations in cells upon AgNPs and GO exposure, which was primarily ascribed to DNA methylation variations at the genome scale.

Herein, we studied the genome-wide DNA methylation changes along with toxicological and physiological assessments of cells in response to a collection of ENMs with high exposure potential. Exposure to AgNPs and $\mathrm{GO}$ greatly increased the global 5-mC level, in contrast to a much milder change for AuNPs, CNTs, $\mathrm{nTiO}_{2}$, and nZnO. The different capabilities of these ENMs to alter DNA methylation could be attributed to their fundamental differences in physicochemical properties. MeDIP-Seq analysis along with BSP uncovered ENM-induced considerable changes of DNA methylation with basepair resolution. Pathway modeling and gene expression analysis demonstrated that a myriad of biological processes were affected, including most prominently the plasma membrane-associated receptors and components, cytoskeleton and adhesion/junctionrelated proteins, ion channels/transporters, and energy homeostasis pathways. Moreover, there was also a pronounced difference in these responsive pathways between AgNPs and GO in both cell types, such as differentially methylated genes responsible for the gap junction in AgNP-treated cells in contrast to differentially methylated genes responsible for substance metabolism in GO-treated cells. These results also signified the importance of the fundamental physicochemical properties in dictating the alterations of DNA methylation. In the meantime, there was a difference between these two cell types in the responsive signaling pathways, which should be accounted for their differential cellular origin and their distinct propensity. Thus,

diagram depicting AOPs and adaptive/compensatory signaling due to ENM-conducted alterations of DNA methylation at the genome-wide scale in cells under low-dose exposure. $*: P<0.05$, relative to untreated control. 
these findings also suggested that the mechanisms in response to ENMs vary across cell types.

Although previous studies showed that the DNA methylation status could be altered by various chemicals, the possible molecular bases underlying these effects have not been fully understood. [36] Cellular stress, inflammation, and DNA damage are demonstrated to contribute to chemical-induced DNA methylation, ${ }^{[4,37]}$ whereas more efforts are needed to define the general mechanisms. Although some preliminary studies suggested that ENM treatment could alter the DNA methylation status, ${ }^{[7,38]}$ the underlying mechanisms have not been explored yet. There may be similar mechanisms between ENMs and certain chemicals in inducing DNA methylation changes; however, future work is needed to address the similarities and differences. In the current work, we deciphered the molecular mechanisms (at least partially) responsible for ENM-induced DNA methylation variations: the changes of the DNMT enzymes and TET proteins contributed to the global alterations of DNA methylation. These findings thus implied that the processes of both methylation and demethylation are vulnerable to ENM exposure. Nonetheless, other possible mechanisms still require further investigation.

In summary, our study depicted the scenario where sublethal ENMs induced alterations of various cellular processes and pathways due to DNA methylation changes, which primarily accounted for the cytotoxicity and adaptive/compensatory responses. These findings offered in-depth insights into the mode of action and cellular/molecular events upon ENM exposures and provided a solid foundation for the development of AOPs in determining the toxicity and health risks of ENMs due to genome-wide DNA methylation changes (Figure 5G). These findings may also have the potential to be generalized to other forms of ENMs under low-dose exposure settings. Thus, the variations of genome-wide DNA methylation responding to ENMs represent an early and more sensitive surrogate to identify ENM-induced direct and indirect effects that may be overlooked by the traditional toxicity assays.

\section{Experimental Section}

Preparation and Characterization of ENMs: AgNPs coated with polyvinylpyrrolidone were purchased from Huzheng Nanotechnology Co., Ltd. (Shanghai, China). AuNPs with citrate coating were synthesized from $15 \mathrm{~nm}$ AuNPs using the seed growth method, ${ }^{[39]}$ arriving at an overall size of $50 \mathrm{~nm}$. Multiwall CNTs modified with a carboxyl group $(\mathrm{COOH})$ were synthesized using an established method. ${ }^{[40]}$ CNT samples were sonicated for $15 \mathrm{~min}$, and the obtained suspensions were saved for further dilution. For the preparation of various $\mathrm{GO}$ samples, our previous protocol was followed. ${ }^{[28,31]} \mathrm{nTiO}_{2}$ (Degussa P-25 particles) and $\mathrm{nZnO}$ particles (Nanostructured and Amorphous Materials, Houston, USA) were added in $\mathrm{dd}_{2} \mathrm{O}$, followed by sonication prior to further dilution for characterization and exposure experiments. The morphology of ENMs was visualized by TEM (Hitachi H-7500, Japan). Hydrodynamic diameter and Zeta-potential in $\mathrm{dd}_{2} \mathrm{O}$ and culture medium were measured by a Zetasizer (Malvern Nano series, UK). For $\mathrm{GO}$, Atomic Force Microscope (AFM) images were taken in the contact mode on an AFM 5500 (Agilent, USA). The Fourier transform infrared (FTIR) spectrum of GO was obtained on a $6700 \mathrm{FTIR}$ spectrophotometer (PerkinElmer, USA). GO materials were deposited on the silicon wafers and air dried, followed by their X-ray photoelection spectroscopy examination.

Cell Culture: A549, 293T, and THP-1 cells were purchased from the Shanghai Cell Bank of Type Culture Collection (Shanghai, China). Cells were cultured in Dulbecco's modified Eagle medium (Gibco, USA) or RPMI-1640 medium (Gibco, USA) supplemented with 10\% fetal bovine serum (Gibco, USA) and $100 \mathrm{U} \mathrm{mL}^{-1}$ penicillin-streptomycin (Hyclone, USA) at $37{ }^{\circ} \mathrm{C}$ and with $5 \% \mathrm{CO}_{2}$. To initiate differentiation, THP-1 cells were treated with $200 \mathrm{~nm}$ Phorbol-12-myristate-13-acetate overnight.

Cellular Localization of ENMs by TEM: After treatment with different ENMs for $24 \mathrm{~h}$, collected cells were washed three times with phosphate buffer saline (PBS), and fixed in $2.5 \%$ glutaraldehyde, followed by further treatment with pure resin and embedding into beem capsules with pure resin. Ultrathin sections $(70 \mathrm{~nm})$ were cut and stained with $1 \%$ lead citrate and $0.5 \%$ uranyl acetate and then examined with a high-resolution transmission electron microscope (JEOL JEM 2010F, Hitachi, Japan).

Cell Viability Assessment: Cells were treated with ENMs at different concentrations for $24 \mathrm{~h}$. Cell viability was assayed by cell counting with 24-well plates or Alamar Blue assay with 96-well plates. For the Alamar Blue assay, resazurin (Sigma, USA) was added into each well at a final concentration of $10 \%$ for an additional $2 \mathrm{~h}$. Thereafter, fluorescence intensity was recorded with an excitation wavelength at $530 \mathrm{~nm}$ and an emission wavelength at $590 \mathrm{~nm}$ on a microplate reader (Thermo Fisher Scientific, USA).

UPLC-MS/MS Analysis of 5-mC and 5-hmC Levels in Genomic DNA: Genomic DNA was extracted from cells posttreatment with ENMs using a DNA isolation kit according to the manufacturer's instructions (Qiagen, Germany). Afterward, $10 \mu \mathrm{g}$ of genomic DNA was digested with DNase I (Thermo Fisher Scientific, USA), snake venom phosphodiesterase I (Sigma, USA), and calf intestinal phosphatase (New England Biolabs, USA) at $37^{\circ} \mathrm{C}$ for $12 \mathrm{~h}$. Digested DNA was purified by removing the enzymes, followed by UPLC-MS/MS analysis, as described previously. ${ }^{[4]]}$ In brief, the Dionex Ultimate 3000 UPLC system was coupled to a TSQ Quantiva Ultra triple-quadrupole mass spectrometer (Thermo Fisher Scientific, USA), equipped with a heated electrospray ionization probe in the positive ion mode. Samples were separated at a flow rate of $200 \mu \mathrm{L} \mathrm{min}{ }^{-1}$ by an ACQUITY UPLC HSS T3 column $(2.1 \times 100 \mathrm{~mm}, 1.8 \mu \mathrm{m}$, Waters). A binary solvent system was used, where the mobile phase $A$ consisted of $2 \times 10^{-3} \mathrm{M}$ ammonium acetate and $\mathrm{H}_{2} \mathrm{O}$, and the mobile phase $\mathrm{B}$ consisted of $100 \%$ acetonitrile. Readouts were acquired in selected reaction monitoring for $5-\mathrm{hmC}$ and 5-mC with transitions of 258/124 and 242/126, respectively. Data analysis and quantitation were performed using the software Xcalibur 3.0.63 (Thermo Fisher Scientific, USA).

Dot-blotting Assay: Concentrations of genomic DNA were quantified by Nanodrop 2000 (Thermo Fisher Scientific, USA). The same amount of DNA samples were denatured at $95{ }^{\circ} \mathrm{C}$ for $10 \mathrm{~min}$, and twofold serial dilutions of DNA samples were spotted on the nitrocellulose membranes soaked with $2 x$ saline sodium citrate ( $2 x$ SSC) buffer. Thereafter, the nitrocellulose membranes were baked at $80{ }^{\circ} \mathrm{C}$ for $2 \mathrm{~h}$, followed by blocking with $5 \%$ skimmed milk at room temperature for $1 \mathrm{~h}$. The membranes were incubated with anti-5-mC (1:1000) Ab or anti5-hmC Ab (1:2000, both from the Active Motif, USA) at $4{ }^{\circ} \mathrm{C}$ overnight. After incubation with according secondary $A b$, autoradiogram images were acquired and analyzed using a ChemiDoc X-ray Raman scattering (XRS) chemiluminescence system (Bio-RAD, USA).

MeDIP-Seq Analysis: MeDIP-seq was performed by the BGI Tech, Inc. (http://www.bgi.com/us/). Genomic DNA for each sample was isolated and purified, which was then sonicated into 100-500 bp fragments. DNA-end repair was implemented through 3'-A overhang and ligation of sequencing adaptors. DNA samples were denatured at $95{ }^{\circ} \mathrm{C}$ for $10 \mathrm{~min}$, and an aliquot $(5 \mu \mathrm{g})$ of DNA was immunoprecipitated with anti-5-mC $\mathrm{Ab}$ at $4{ }^{\circ} \mathrm{C}$ overnight. The eluted products were separated and extracted, and the extracted DNA was validated and amplified with PCR. Further processing and bioinformatics analysis of the sequencing libraries were carried out at the BGI Tech.

Gene Ontology and Pathway Analysis: Gene ontology analysis was performed using quick $\mathrm{GO}$ database within the Interpro bioinformatics 
database (http://www.geneontology.org). The Pathway analysis was carried out using the KEGG database (http://www.genome.jp/kegg).

Bisulfite Sequencing Analysis: Bisulfite conversion of genomic DNA was carried out with an EZ DNA Methylation-Gold Kit (ZYMO Research, USA) according to the manufacturer's instructions. The bisulfate-treated DNA samples were then subjected to PCR amplification. PCR primers are listed in Table S1 (Supporting Information). After a series of processes including alkaline phosphatase treatment, in vitro transcription and RNase digestion, the final products were purified and analyzed using mass spectrometry that was equipped with the EpiTYPER software.

RT-qPCR Analysis: Total RNAs were isolated from cells with Trizol reagent (Invitrogen, USA). Relative gene expression was appraised with SYBR Green qPCR master mix (Promega, USA) on a Bio-RAD qPCR instrument. Primer sequences are provided in Table S2 (Supporting Information).

Intracellular ROS Production: At 1, 3, 6, and $24 \mathrm{~h}$ posttreatment, $10 \mu \mathrm{m}$ dichlorofluorescein diacetate (Sigma, USA) was added into each well in the dark. After incubation at $37{ }^{\circ} \mathrm{C}$ for $30 \mathrm{~min}$, cells in 96 -well plates were washed with PBS for three times, and the fluorescence was then detected at $525 \mathrm{~nm}$ using an excitation wavelength of $488 \mathrm{~nm}$ on a microplate reader.

Mitochondrial Superoxide Detection: After treatment, MitoSox Red (Invitrogen, USA) was added into cells at a final concentration of $5 \times 10^{-6} \mathrm{M}$ at $37^{\circ} \mathrm{C}$ for $10 \mathrm{~min}$. Thereafter, cells were washed with warm PBS for three times, and the fluorescence was analyzed on a NovoCyte 1040 flow cytometry (ACEA BIO, China) or on a microplate reader following the manufacturer's instructions.

Evaluation of DNA Damage: Levels of $\gamma-\mathrm{H} 2 \mathrm{AX}$ and 8-oxo-7,8-dihydro2 '-deoxyguanosine (8-oxo-G) were used to assess DNA damage. Total proteins were extracted from cells treated with ENMs for $24 \mathrm{~h}$, and then $\gamma-\mathrm{H} 2 \mathrm{AX}$ concentration was examined by Western blotting. For the detection of 8-oxo-G, cell culture medium was collected after ENM exposure for $24 \mathrm{~h}$, and the supernatants after centrifugation were subjected to the detection of 8-oxo-G with a commercial kit (Dongge Biotechnology, China).

Western Blot Analysis: Collected cells posttreatment were washed with cold PBS and were then lysed with RIPA lysis buffer containing the protease inhibitor cocktail (Roche, Switzerland). Equal amounts of total proteins were subjected to $8-12 \%$ sodium dodecyl sulfate-polyacrylamide gel electrophoresis (SDS-PAGE), followed by Western blotting, as previously described.[42] Primary Abs were against GAPDH (1:1000, Santa Cruz Biotechnology, USA), DNMT1 (1:1000, Cellular Signaling Technology, USA), DNMT3A (1:1000, Santa Cruz Biotechnology, USA), TET1 (1:1000, GeneTex, USA), TET2 (1:200, Santa Cruz Biotechnology, USA), and $\gamma-\mathrm{H} 2 \mathrm{AX}(1: 1000$, Active Motif, USA). Autoradiogram signal was detected on a ChemiDoc XRS chemiluminescence system.

Examination of Cellular Membrane Permeability: After treatment, cells were stained with $\mathrm{PI}$ or To-Pro- 3 at a final concentration of $4 \times 10^{-6}$ or $1 \times 10^{-6} \mathrm{M}$, respectively. After incubation in the dark at room temperature for $10 \mathrm{~min}$, cells were washed with cold PBS twice. The fluorescence was visualized on a TCS SP5 laser scanning confocal microscope. PI or To-Pro-3 fluorescence was detected at 617 or $670 \mathrm{~nm}$, respectively. Meanwhile, a LDH release assay was performed. Briefly, cell culture medium was collected after ENM-treatment and was then centrifuged at $12000 \mathrm{~g}$. The supernatants were saved for the assay of LDH release with a LDH assay kit according to manufacturer's instructions (Nanjing Jiancheng, China).

Assessment of Cytoskeleton: After treatment, cells were washed with PBS and fixed with $4 \%$ formaldehyde for $10 \mathrm{~min}$, followed by permeabilization with $2 \%$ Triton X-100 for 5 min. After washing, the cytoskeleton was stained with phalloidin-Ffuorescein isothiocyanate (FITC, green), and nuclei were stained with 2-(4-Amadinophenyl)-6indolecarbamidine dihydrochloride (DAPI, blue). The fluorescence of phalloidin-FITC or DAPI was excited at 488 or $364 \mathrm{~nm}$ and observed at 630 or $430 \mathrm{~nm}$ using a confocal microscope, respectively.

Record of Intracellular $\mathrm{Ca}^{2+}$ Concentration Changes: Intracellular $\mathrm{Ca}^{2+}$ concentration was monitored using the Fluo-3/AM fluorescence probe (Solarbio Biotechnology, China). After cell seeding in six-well plates overnight, cells were exposed to AgNPs and GO for $24 \mathrm{~h}$ in Hank's Balanced Salt Solutions without calcium. Thereafter, cells were washed with PBS three times and then incubated with $2 \times 10^{-6} \mathrm{M}$ Fluo-3/AM in the dark at $37{ }^{\circ} \mathrm{C}$ for $20 \mathrm{~min}$. Finally, cells were collected, and the Fluo-3 fluorescence was recorded through Fluorescence Activating Cell Sorter (FACS) analysis at $526 \mathrm{~nm}$ with the excitation wavelength at $506 \mathrm{~nm}$.

Assessment of Cellular ATP Level: An ATP assay kit was used to assess the cellular ATP levels following the instructions provided by the manufacturer (Beyotime, China). Briefly, cells were seeded in 24-well plates, and thereafter treated with ENMs for $24 \mathrm{~h}$. Afterward, cells were washed with cold PBS and lysed at $4{ }^{\circ} \mathrm{C}$ using the lysis buffer provided by the manufacturer. Collected samples were further subjected to the bioluminescent intensity assay using a microplate reader (Thermo Fisher Scientific, USA).

Quantification of Cellular Total RNAs and Total Proteins: After treatment, the same number of cells $\left(3 \times 10^{5}\right.$ or $6 \times 10^{5}$, respectively) were collected, followed by total RNA and protein extractions with Trizol reagent (Invitrogen, USA) or RIPA lysis buffer, respectively. Thereafter, the RNA concentration was assayed by NanoDrop, and the protein concentration was determined with the Lowry method.

Statistical Analysis: Data were shown in mean \pm standard error. Independent $t$-test was used to compare the difference between two samples, while one-way ANOVA was for determining the difference among multiple $(>2)$ samples. $P$-values were calculated to quantify the statistical significance.

\section{Supporting Information}

Supporting Information is available from the Wiley Online Library or from the author.

\section{Acknowledgements}

This work was supported by grants under the national "973" program (Grant No. 2014CB932000), the Strategic Priority Research Program of the Chinese Academy of Sciences (Grant No. XDB14000000), grants from the National Natural Science Foundation of China (Grant Nos. 21425731, 21377159, 21637004, and 81402092), Tianjin Research Program of Application Foundation and Advanced Technology (Grant No. 15JCQNJC08200), and Tianjin High School Science and Technology Fund Planning Project (Grant No. 20140119).

Received: August 26, 2016

Revised: October 15, 2016

Published online: December 5, 2016

[1] a) K. Chaloupka, Y. Malam, A. M. Seifalian, Trends Biotechnol. 2010 28, 580; b) Z. Chen, S. M. Tabakman, A. P. Goodwin, M. G. Kattah, D. Daranciang, X. R. Wang, G. Y. Zhang, X. L. Li, Z. Liu, P. J. Utz, K. L. Jiang, S. S. Fan, H. J. Dai, Nat. Biotechnol. 2008, 26, 1285; c) K. S. Novoselov, V. I. Fal'ko, L. Colombo, P. R. Gellert, M. G. Schwab, K. Kim, Nature 2012, 490, 192.

[2] a) G. Vecchio, M. Fenech, P. P. Pompa, N. H. Voelcker, Small 2014, 10, 2721; b) N. Singh, B. Manshian, G. J. Jenkins, S. M. Griffiths, P. M. Williams, T. G. Maffeis, C. J. Wright, S. H. Doak, Biomaterials 2009, 30, 3891; c) A. E. Nel, L. Madler, D. Velegol, T. Xia, E. M. Hoek, P. Somasundaran, F. Klaessig, V. Castranova, M. Thompson, Nat. Mater. 2009, 8, 543; d) C. Watson, J. Ge, J. Cohen, G. Pyrgiotakis, B. P. Engelward, P. Demokritou, ACS Nano 2014, 8, 2118; e) E. Valsami-Jones, I. Lynch, Science 2015, 
350, 388; f) H. F. Krug, Angew. Chem. Int. Ed. Engl. 2014, 53, 12304.

[3] Z. Wang, T. Xia, S. J. Liu, Nanoscale 2015, 7, 7470.

[4] S. Shyamasundar, C. T. Ng, L. Y. Yung, S. T. Dheen, B. H. Bay, Epigenomics 2015, 7, 395.

[5] a) A. B. Djurisic, Y. H. Leung, A. M. Ng, X. Y. Xu, P. K. Lee, N. Degger, R. S. Wu, Small 2015, 11, 26; b) C. J. Johnson, N. Zhukovsky, A. E. Cass, J. M. Nagy, Proteomics 2008, 8, 715.

[6] a) T. Inagaki, J. Sakai, S. Kajimura, Nat. Rev. Mol. Cell Biol., 17, 480; b) E. A. Saunderson, H. Spiers, K. R. Mifsud, M. Gutierrez-Mecinas, A. F. Trollope, A. Shaikh, J. Mill, J. M. Reul, Proc. Natl. Acad. Sci. USA 2016, 113, 4830; c) R. A. Stein, J. Epidemiol. Community Health 2012, 66, 8; d) W. L. Bai, Y. J. Chen, A. Gao, Int. J. Nanomed. 2015, 10, 5561; e) C. M. Gong, G. H. Tao, L. Q. Yang, J. J. Liu, Q. C. Liu, W. J. Li, Z. X. Zhuang, Toxicol. Lett. 2012, 209, 264; f) N. Chatterjee, J. Yang, J. Choi, Mutat. Res. Genet. Toxicol. Environ. Mutagen. 2016, 798-799, 1; g) C. M. Gong, G. H. Tao, L. Q. Yang, J. J. Liu, Q. C. Liu, Z. J. Zhuang, Biochem. Biophys. Res. Commun. 2010, 397, 397.

[7] a) X. Lu, I. R. Miousse, S. V. Pirela, S. Melnyk, I. Koturbash, P. Demokritou, Nanotoxicology 2016, 10, 140; b) X. Lu, I. R. Miousse, S. V. Pirela, J. K. Moore, S. Melnyk, I. Koturbash, P. Demokritou, Nanotoxicology 2016, 10, 629.

[8] A. Bird, Genes Dev. 2002, 16, 6 .

[9] a) D. Pissuwan, T. Niidome, Nanoscale 2015, 7, 59; b) A. Pinsino, R. Russo, R. Bonaventura, A. Brunelli, A. Marcomini, V. Matranga, Sci. Rep. 2015, 5, 14492; c) M. Li, L. Z. Zhu, D. H. Lin, Environ. Sci. Technol. 2011, 45, 1977; d) P. A. Holden, F. Klaessig, R. F. Turco, J. H. Priester, C. M. Rico, H. Avila-Arias, M. Mortimer, K. Pacpaco, J. L. Gardea-Torresdey, Environ. Sci. Technol. 2014, 48, 10541.

[10] P. Muralidharan, M. Malapit, E. Mallory, D. Hayes Jr., H. M. Mansour, Nanomedicine 2015, 11, 1189

[11] a) A. A. Burns, J. Vider, H. Ow, E. Herz, O. Penate-Medina, M. Baumgart, S. M. Larson, U. Wiesner, M. Bradbury, Nano Lett. 2009, 9, 442; b) Q. J. He, Z. W. Zhang, F. Gao, Y. P. Li, J. L. Shi, Small 2011, 7, 271.

[12] a) J. V. Castell, M. T. Donato, M. J. Gomez-Lechon, Exp. Toxicol. Pathol. 2005, 57, 189; b) H. Nakagawa, J. Inorg. Biochem. 2013, 118,187 ; c) O. Bondarenko, K. Juganson, A. Ivask, K. Kasemets, M. Mortimer, A. Kahru, Arch. Toxicol. 2013, 87, 1181.

[13] a) S. A. Ha, H. K. Kim, J. Yoo, S. Kim, S. M. Shin, Y. S. Lee, S. Y. Hur, Y. W. Kim, T. E. Kim, Y. J. Chung, S. S. Jeun, D. W. Kim, Y. G. Park, J. Kim, S. Y. Shin, Y. H. Lee, J. W. Kim, BMC Cell Biol. 2010, 11, 49; b) R. Moreno-Sanchez, A. Marin-Hernandez, E. Saavedra, J. P. Pardo, S. J. Ralph, S. Rodriguez-Enriquez, Int. J. Biochem. Cell Biol. 2014, 50, 10.

[14] a) V. Castranova, P. A. Schulte, R. D. Zumwalde, Acc. Chem. Res. 2013, 46, 642; b) E. D. Kuempel, V. Castranova, C. L. Geraci, P. A. Schulte, J. Nanopart. Res. 2012, 14, 1029; c) J. H. Han, E. J. Lee, J. H. Lee, K. P. So, Y. H. Lee, G. N. Bae, S.-B. Lee, J. H. Ji, M. H. Cho, I. J. Yu, Inhalation Toxicol. 2008, 20, 741; d) I. Guseva Canu, T. F. Bateson, V. Bouvard, M. Debia, C. Dion, K. Savolainen, I. J. Yu, Int. J. Hyg. Environ. Health 2016, 219, 166.

[15] a) X. X. Zhou, R. Liu, J. F. Liu, Environ. Sci. Technol. 2014, 48, 14516; b) Z. X. Luo, Z. H. Wang, Q. Z. Li, Q. K. Pan, C. Z. Yan, F. Liu, J. Environ. Monit. 2011, 13, 1046; c) R. Kaegi, B. Sinnet, S. Zuleeg, H. Hagendorfer, E. Mueller, R. Vonbank, M. Boller, M. Burkhardt, Environ. Pollut. 2010, 158, 2900; d) A. Weir, P. Westerhoff, L. Fabricius, K. Hristovski, N. von Goetz, Environ. Sci. Technol. 2012, 46, 2242; e) A. P. Gondikas, F. von der Kammer, R. B. Reed, S. Wagner, J. F. Ranville, T. Hofmann, Environ. Sci. Technol. 2014, 48, 5415; f) M. A. Kiser, P. Westerhoff, T. Benn, Y. Wang, J. Perez-Rivera, K. Hristovski, Environ. Sci. Technol. 2009, 43,
6757; g) R. D. Holbrook, D. Motabar, O. Quifiones, B. Stanford, B. Vanderford, D. Moss, Environ. Pollut. 2013, 181, 68.

[16] S. Kriaucionis, N. Heintz, Science 2009, 324, 929.

[17] a) R. Jaenisch, A. Bird, Nat. Genet. 2003, 33, 245; b) Z. D. Smith, A. Meissner, Nat. Rev. Genet. 2013, 14, 204; c) J. A. Law, S. E. Jacobsen, Nat. Rev. Genet. 2010, 11, 204.

[18] H. Kawasaki, Inhalation Toxicol. 2015, 27, 363.

[19] P. A. Jones, G. Liang, Nat. Rev. Genet. 2009, 10, 805.

[20] A. M. Deaton, A. Bird, Genes Dev. 2011, 25, 1010.

[21] a) W. W. Li, M. Liu, J. Nucleic Acids 2011, 2011, 870726; b) M. L. Chen, F. Shen, W. Huang, J. H. Qi, Y. Wang, Y. Q. Feng, S. M. Liu, B. F. Yuan, Clin. Chem. 2013, 59, 824; c) S. G. Jin, Y. Jiang, R. Qiu, T. A. Rauch, Y. Wang, G. Schackert, D. Krex, Q. Lu, G. P. Pfeifer, Cancer Res. 2011, 71, 7360.

[22] J. U. Guo, Y. Su, C. Zhong, G. L. Ming, H. Song, Cell 2011, 145, 423.

[23] H. S. Guo, P. Zhu, L. Y. Yan, R. Li, B. Q. Hu, Y. Lian, J. Yan, X. L. Ren, S. L. Lin, J. S. Li, X. H. Jin, X. D. Shi, P. Liu, X. Y. Wang, W. Wang, Y. Wei, X. L. Li, F. Guo, X. L. Wu, X. Y. Fan, J. Yong, L. Wen, S. X. Xie, F. C. Tang, J. Qiao, Nature 2014, 511, 606.

[24] a) J. M. Ryu, H. J. Han, Stem Cells 2015, 33, 819; b) J. Ezan, L. Lasvaux, A. Gezer, A. Novakovic, H. May-Simera, E. Belotti, A. C. Lhoumeau, L. Birnbaumer, S. Beer-Hammer, J. P. Borg, A. Le Bivic, B. Nurnberg, N. Sans, M. Montcouquiol, Nat. Cell Biol. 2013, 15, 1107.

[25] a) D. I. Lee, G. Zhu, T. Sasaki, G. S. Cho, N. Hamdani, R. Holewinski, S. H. Jo, T. Danner, M. Zhang, P. P. Rainer, D. Bedja, J. A. Kirk, M. J. Ranek, W. R. Dostmann, C. Kwon, K. B. Margulies, J. E. Van Eyk, W. J. Paulus, E. Takimoto, D. A. Kass, Nature 2015, 519, 472; b) J. Kim, G. Song, G. Y. Wu, F. W. Bazer, Proc. Natl. Acad. Sci. USA 2012, 109, 1619.

[26] a) S. George, S. J. Lin, Z. X. Ji, C. R. Thomas, L. J. Li, M. Mecklenburg, H. Meng, X. Wang, H. Y. Zhang, T. Xia, J. N. Hohman, S. Lin, J. I. Zink, P. S. Weiss, A. E. Nel, ACS Nano 2012, 6, 3745; b) Z.-M. Xiu, Q.-B. Zhang, H. L. Puppala, V. L. Colvin, P. J. J. Alvarez, Nano Lett. 2012, 12, 4271.

[27] a) W. B. Hu, C. Peng, M. Lv, X. M. Li, Y. J. Zhang, N. Chen, C. H. Fan, Q. Huang, ACS Nano 2011, 5, 3693; b) Q. X. Mu, G. X. Su, L. W. Li, B. O. Gilbertson, L. H. Yu, Q. Zhang, Y.-P. Sun, B. Yan, ACS Appl. Mater. Interface 2012, 4, 2259.

[28] J. Ma, R. Liu, X. Wang, Q. Liu, Y. N. Chen, R. P. Valle, Y. Y. Zuo, T. Xia, S. J. Liu, ACS Nano 2015, 9, 10498.

[29] Y. Chen, Z. Wang, M. Xu, X. Wang, R. Liu, Q. Liu, Z. H. Zhang, T. Xia, J. C. Zhao, G. B. Jiang, Y. Xu, S. J. Liu, ACS Nano 2014, 8, 5813.

[30] S. J. Yu, J. B. Chao, J. Sun, Y. G. Yin, J. F. Liu, G. B. Jiang, Environ. Sci. Technol. 2013, 47, 3268

[31] M. Xu, J. Q. Zhu, F. F. Wang, Y. J. Xiong, Y. K. Wu, Q. Q. Wang, J. Weng, Z. H. Zhang, W. Chen, S. J. Liu, ACS Nano 2016, 10, 3267.

[32] C. Y. Wu, C. Wang, J. Zheng, C. Luo, Y. F. Li, S. W. Guo, J. Y. Zhang, ACS Nano 2015, 9, 7913.

[33] V. Jurisic, S. Radenkovic, G. Konjevic, Adv. Exp. Med. Biol. 2015, 867, 115.

[34] a) M. E. Kotas, R. Medzhitov, Cell 2015, 160, 816; b) S. N. Fu, L. Yang, P. Li, O. Hofmann, L. Dicker, W. Hide, X. H. Lin, S. M. Watkins, A. R. Ivanov, G. S. Hotamisligil, Nature 2011, 473, 528.

[35] a) M. F. Carey, C. L. Peterson, S. T. Smale, Transcriptional Regulation in Eukaryotes: Concepts, Strategies, and Techniques, 2nd ed., Cold Spring Harbor, New York, NY 2009; b) M. B. Mathews, N. Sonenberg, J. W. B. Hershey, Translational Control in Biology and Medicine, Cold Spring Harbor, New York, NY 2007.

[36] L. F. Hou, X. Zhang, D. Wang, A. Baccarelli, Int. J. Epidemiol. 2012, $41,79$. 
[37] a) C. Yauk, A. Polyzos, A. Rowan-Carroll, C. M. Somers, R. W. Godschalk, F. J. Van Schooten, M. L. Berndt, I. P. Pogribny, I. Koturbash, A. Williams, G. R. Douglas, O. Kovalchuk, Proc. Natl. Acad. Sci. USA 2008, 105, 605; b) A. Stoccoro, H. L. Karlsson, F. Coppede, L. Migliore, Toxicology 2013, 313, 3.

[38] a) F. Gao, N. J. Ma, H. Zhou, Q. Wang, H. Zhang, P. Wang, H. L. Hou, H. Wen, L. J. Li, Int. J. Nanomed. 2016, 11, 3859; b) J. Y. Li, M. P. Tian, L. Cui, J. Dwyer, N. J. Fullwood, H. Q. Shen, F. L. Martin, Sci. Rep. 2016, 6, 20207; c) J. Blanco, D. Lafuente, M. Gomez, T. Garcia, J. L. Domingo, D. J. Sanchez, Arch. Toxicol. DOI: $10.1007 / \mathrm{s} 00204-016-1773-0$.
[39] N. Jana, L. Gearheart, C. Murphy, Chem. Mater. 2001, 13, 2313.

[40] N. N. Gao, Q. Zhang, Q. X. Mu, Y. H. Bai, L. W. Li, H. Y. Zhou, E. R. Butch, T. B. Powell, S. E. Snyder, G. B. Jiang, B. Yan, ACS Nano 2011, 5, 4581.

[41] R. C. Yin, S.-Q. Mao, B. L. Zhao, Z. C. Chong, Y. Yang, C. Zhao, D. P. Zhang, H. Huang, J. Gao, Z. Li, Y. Jiao, C. P. Li, S. Q. Liu, D. N. Wu, W. K. Gu, Y.-G. Yang, G.-L. Xu, H. L. Wang, J. Am. Chem. Soc. 2013, 135, 10396.

[42] Y. Chen, Z. Zhang, K. Yang, J. Du, Y. Xu, S. Liu, Oncogene 2015, 34, 3839. 